\title{
OPTIMIZING NATURE-BASED FEATURES FOR WAVE DISSIPATION AND LAND- WATER CONNECTIVITY
}

\author{
Maura Boswell, Old Dominion University, mbosw002@odu.edu \\ Navid Tahvildari., Old Dominion University, ntahvild@odu.edu
}

\begin{abstract}
BACKGROUND
Living shorelines integrate structural and natural features to stabilize the shoreline, through reduction of erosion from the wave climate, while keeping the connectivity between land and aquatic ecosystems. This study includes field study for two different types of living shoreline systems to quantify and compare their wave dissipation services and provide physics-based guidance for the design of living shoreline systems that are efficient in wave dissipation yet maximize land-water connectivity.
\end{abstract}

\section{METHODS}

Data were collected from a marsh sill living shoreline and an oyster reef living shoreline in Virginia. An offshore wave gage was deployed near each project site to capture the localized wave climate and pressure transducers were located along four profiles at each site to capture wave dissipation. Data from the gauges were analyzed and used to calibrate and validate a phaseresolving nonhydrostatic numerical wave model. The validated model is used to examine the dependency of wave dissipation on structure dimensions, and to determine ways for maximizing land-water connectivity.

\section{FIELD STUDY}

The research study utilizes field observations to determine the hydrodynamics of wave interaction with structures along two different types of living shoreline projects. The first site includes a marsh-sill and is located in the Severn River sub-estuary of Virginia. This project was constructed in 2016 and consists of four rock sills, sand fill, and vegetation adjacent to an eroding marsh. The second site is the Bayford Oyster Castle Project site in the Nassawadox Creek located in the Eastern Shore of Virginia. This project was also constructed in 2016 and consists of two separate lines of bio-engineered oyster reefs with the intent of restoring oyster reef habitat and providing shoreline erosion protection.

An Acoustic Doppler Current Profiler (ADCP) was deployed offshore of the project sites in approximately six feet of water to capture the nearshore waves that approach the living shoreline projects. Two Optical Backscatter Sensor (OBS) gauges were used in the oyster reef site to measure changes in suspended sediment. Additionally, up to nine pressure transducers were placed at each site along four profiles, including seaward of the structures, immediately landward of the structures. The data reveals spatial variability of water levels in living shoreline treatments. Observations were made on the water surface elevation across living shoreline profiles (around structures, in the gaps between structure, and over planted marshes) to measure wave dissipation rates by structures. Data from the gauges were processed using the Fast Fourier Transform (FFT) analysis and energy dissipation in different frequencies of the wave spectrum was quantified. Collecting data from two different types of living shorelines enabled analyses to be conducted to determine the effects of gap width and crest height on wave dissipation. The field data were used to calibrate and validate the numerical model.

\section{NUMERICAL MODELING}

The nonhydrostatic phase-resolving numerical model, NHWAVE (Ma et al., 2012), is employed to investigate the dependency of wave dissipation on important parameters associated with structures in living shorelines. NHWAVE is a three-dimensional model that has been used, among many other applications, to simulate the interactions between coastal waves and porous structures (Ma et al., 2014). In order to predict wave dissipation, the model is calibrated for parameters that represent dissipation due to structure and bottom friction. The data on wave dissipation for each site is used for this purpose and site-specific parameters are obtained. The rock sill structures in this study are typically emergent features, whereas the oyster reefs are lower profile structures. While the typical marsh sill living shoreline has a single structure with the crest height determined based on the design wave height, this study examined how having multiple parallel lower profile structures affects the wave dissipation and sediment resuspension in the system. Additionally, the array of oyster reefs provide valuable data regarding water level variability and current patterns with parallel, overlapping structures that are incorporated into the numerical analyses.

\section{REFERENCES}

Ma, Shi, Hsiao, and Wu (2014): Non-hydrostatic modeling of wave interactions with porous structures, Coastal Engineering, ELSEVIER, vol. 91, pp. 84-98.

Ma, Shi, and Kirby (2012): Shock-capturing nonhydrostatic model for fully dispersive surface wave processes, Ocean Modeling, ELSEVIER, vol. 43, pp. 2235. 